\title{
Changes in prevalence of psychotropic drug use and alcohol consumption among the elderly in Germany: results of two National Health Interview and Examination Surveys 1997-99 and 2008-11
}

\author{
Ingrid-Katharina Wolf ${ }^{*+} \mathbb{D}$, Yong $\mathrm{Du}^{\dagger}$ and Hildtraud Knopf
}

\begin{abstract}
Background: Psychotropic drug use and alcohol consumption among older adults need to be monitored over time as their use or combined use bears risks of harms. Representative data on changes in prevalence, patterns and co-relates of substance use are lacking in Germany.

Methods: Participants were older adults (60-79 years) from two German National Health Surveys: 1997-99 (GNHIES98, $N=1,606)$ and 2008-11 (DEGS1, $N=2,501$ ). Included were drugs acting on the nervous system used during the last 7 days. Alcohol consumption was measured by frequency (daily drinking) and quantity (risky drinking: $\geq 20 / 10 \mathrm{~g} /$ day alcohol for men/women). Changes in prevalence adjusted for potential socio-economic and health-related confounders were calculated by logistic regression models approximated by the SAS LSMEANS statement.

Results: The prevalence of overall psychotropic drug use (20.5\% vs. $21.4 \%)$ remained constant between the two surveys. Significant changes were observed in the use of some psychotropics (all GNHIES98 vs. DEGS1): Synthetic antidepressants (3.9\% vs. 6.9\%), St. John's wort (2.9\% vs. $1.1 \%)$, benzodiazepines (3.7\% vs. $2.5 \%$ ), benzodiazepine related drugs ( $0.2 \%$ vs. $0.8 \%)$, narcotic analgesics (3.0\% vs. $4.1 \%)$, anti-dementia drugs (2.2\% vs. $4.2 \%)$ and antiepileptics (1.0\% vs. 2.3\%). Significant changes were also observed in long-term use of synthetic anti-depressants (3.2\% vs. $5.9 \%)$, St. John's wort (2.0\% vs. $0.6 \%)$ and opioid analgesics (1.0\% vs. $2.2 \%)$. Further, we found significant changes in benzodiazepines use (3.3\% vs. $1.4 \%$ ) among men, opioids use (2.9\% vs. $7.3 \%)$ among people with a lower social status, and overall psychotropics ( $26.8 \%$ vs. $32.5 \%)$ as well as opioids use (4.4\% vs. $8.1 \%)$ among those with a worse health status. Moderate alcohol consumption increased significantly (58.0\% vs. 66.9\%). Risky drinking remained unchanged (16.6\% vs. 17.0\%). In spite of significant increases in daily alcohol drinking (13.2\% vs. 18.4\%) psychotropic drug use combined with daily drinking remained unchanged (1.8\% vs. $2.7 \%$ ).

Conclusions: Although prevalence of overall psychotropic drug use remained stable, changes in the use of some psychotropic drug groups and alcohol consumption patterns have been observed. Further studies are required to investigate resulting health consequences and public health relevance of those outcomes.
\end{abstract}

Keywords: Changes, Psychotropic drugs, Alcohol, National health surveys, Older adults, Germany

\footnotetext{
* Correspondence: wolfi@rki.de

${ }^{\dagger}$ Equal contributors

Department of Epidemiology and Health Monitoring, Robert Koch Institute,

General-Pape-Str. 64-66, D-12101 Berlin, Germany
} 


\section{Background}

The prevalence of psychotropic drug and alcoholinteractive medicine use rises sharply with older age [1]. An age-related increase of multi-morbidity and polypharmacy bears higher risks of adverse drug reactions and a reduced drug metabolism in older people aggravates those risks [2]. Potential adverse health outcomes of psychotropic drug use such as falls, strokes or mortality are described in literature [3-5].

The long-term use of some psychotropic drugs, such as opioids and benzodiazepines, can lead to dependency and addiction. With the exception of some medically necessary indications those drugs should be used only for a short period [6, 7].

Psychotropic drugs of phytoceutical origin are also of interest as in Germany the use of alternative medicine has a long tradition and is very common [8].

Alcohol has a psychotropic effect, an addictive potential, and bears health risks for the elderly. According to the Organisation for Economic Co-operation and Development (OECD) alcohol consumption in Germany is with $11 \mathrm{l}$ per capita higher than the average European consumption level of $10 \mathrm{l}$. Additionally, among adults about every sixth woman and about every third man consumes alcohol above tolerable upper levels for healthy adults of 10-12 g/20-24/day for women/men [9, 10]. The combined use of alcohol and psychotropic medicine may aggravate potential risks of both substances [5].

Drug use changes over time as new drugs are introduced into the market and indications for existing drugs might be changed. Also, changes in drug use might be influenced by changes in guidelines for the use of drugs. Transparency on the use of medications and on changes in the use over time is a prerequisite for an informed Public Health Policy.

Prescription data from the statutory health insurance system can provide information on changes in prescription over time but cannot reproduce the real consumption of medicines. Patients might not take all tablets of a package; self-medication and private prescriptions are not recorded by prescription data. Further, health insurance data cannot be linked with a variety of population characteristics, such as socio-economic and health behavior factors (e.g. alcohol consumption).

In Germany, population based data from two comparable surveys - the German National Health Interview and Examination Survey 1997-99 (GNHIES98) and the German Health Interview and Examination Survey for Adults 2008-11 (DEGS1) - with data on the use of psychotropic drugs and alcohol in the older population (60-79 years) are available. A cross-sectional analysis of psychotropic drug use, alcohol consumption and the combined use of both substances based on DEGS1 data has been conducted by the authors recently [11].
Representative population based information on changes over time in psychotropic substance use among the elderly and information on changes in the use of psychotropics according to socio-economic and health-behavior factors are lacking in Germany.

In the present work we analyzed changes in psychotropic drug use, alcohol consumption, and the concomitant use of psychotropic drugs and alcohol between 1997-99 and 2008-11. Additionally, we examined changes in long-term use of selected subgroups of psychotropic drugs. Further, by analyzing changes over time according to socio-economic and health-related factors we identified particularly vulnerable groups among older adults in Germany.

\section{Methods}

\section{Study population}

Analyses conducted in this study were based on data from two nationally representative surveys among noninstitutionalized adults: GNHIES98 (1997-99) and DEGS1 (2008-11). Both surveys were conducted by the Robert Koch Institute (RKI) and followed largely the same sampling strategy and study protocol. This has been described in detail previously [12,13]. Briefly, both surveys recruited participants via a two-stage sampling design. In the first stage a nationwide selection of communities which were representative of location, size, and structure of German communities was conducted (GNHIES98: 120 and DEGS1: 180 communities). In a second stage a representative sample of the 18-79 year old population was drawn from local population registries of the chosen communities. All participants from GNHIES98 $(N=7.124)$ were invited to re-participate in DEGS1. 3,959 women and men (response rate 62\%) followed this invitation. In order to achieve a nationally representative sample 4,193 first time participants were also included in DEGS1 (response rate 42\%), amounting to a total study population of $N=8.152$. Non-responder analyses in both surveys displayed no significant differences between participants and non-participants regarding demographic factors $[14,15]$.

The present analyses focused on men and women aged 60-79 years (GNHIES98: $N=1,615$ and DEGS1: $N=$ 2,508). Among those only participants who completed the interview on medication use were included (GNHIES98: $N=1,606$ and DEGS1: $N=2,501$ ).

\section{Data collection}

Both surveys employed identical data collection methods including self-administered questionnaires, medical examinations, physical measurements, laboratory tests, standardized physician administered computer assisted personal interviews (CAPI), and standardized personal interviews on medicine use [12]. Information on socio- 
demographic factors (e.g. age, sex, region of residence, household size, income, profession, and education) as well as health-related factors (e.g. self-perceived health status, presence of an officially certified disability, and alcohol consumption) was collected via standardized, self-administered questionnaires [12].

\section{Identification of psychotropic drug use and alcohol consumption}

In the invitation letter participants were asked to bring along original packages of the drugs they had taken during the preceding 7 days, including Over-The Counter (OTC) products and dietary supplements. Detailed information on each preparation was recorded by trained health professionals. For all drugs the brand name, indication, frequency (taken when needed or regular), and duration of use were recorded. The preparations were classified by the Anatomical Therapeutic Chemical (ATC) codes. In the present analyses we included drugs belonging to the nervous system class (ATC code N00). The following drug groups were included: Narcotic analgesics (N02A) and aspirin if combined with caffeine (N02BA71), all anti-epileptics (N03), all anti-parkinson drugs (N04), all psycholeptics (N05) with hypnotics and sedatives (N05C), benzodiazepines (N05BA, N05CD, N03AE01)) and benzodiazepine-related drugs (N05CF), all psychoanaleptics (N06) with anti-depressants (N06A) and anti-dementia drugs (N06D), all other nervous system drugs (N07) as well as opiates used as antitussives (ATC code R05DA), and psychotropic drugs with herbal active ingredients (ATC code N05CP or N06AP or N06DP). Excluded were: Other analgesics and antipyretics such as aspirin and paracetamol (ATC code N02B), local anesthetics (ATC code N01B), homeopathic drugs of the ATC class N00, and drugs with indistinctive active ingredients. Concerning frequency and duration of drug use we differentiated between drug use "if needed", "regular, $<3$ months" and "regular, $\geq 3$ months". The cut-off point of $\geq 3$ months for long-term use was chosen as some psychotropic drugs can lead to addiction. Guidelines on the use of opioids in non-cancer pain recommend an application time of no longer than 3 months [6]. The recommendations for limitations in the use of benzodiazepines are even shorter [7, 16]. Anti-depressants have to be taken for a longer period in order to have a therapeutic effect, are usually not taken "only if needed", and their dependency potential is much lower compared to opioids or benzodiazepines [17]. Changes in the prevalence of psychotropic drug use were analyzed for drugs of the above listed ATC classes. Additionally, changes in long-term use were analyzed for the most frequently used drug groups antidepressants, as well as for benzodiazepines and opioids as their long-term use harbors a potential for dependency and addiction.

Alcohol consumption during the preceding 12 months was recorded via a standardized food-frequency questionnaire and was classified according to frequency as well as quantity. Within the classification according to frequency we differentiated between alcohol consumption "at least once a week" (weekly) and "at least once a day" (daily). For the classification according to quantity the mean amount of pure alcohol consumed in grams per day was calculated according to methods previously described [18]. Alcohol consumption according to quantity was classified as "moderate drinking" and "risky drinking". The definition of risky drinking varies greatly internationally [19]. In Germany for healthy younger people a limit of $\geq 10-12$ g/day for women and $\geq 20-24 \mathrm{~g} /$ day for men is assumed $[18,19]$. As older people could be at risk when consuming much smaller amounts of alcohol, and as there are no internationally agreed limits for risky alcohol consumption among the elderly, we adopted the lower limits of $>0$ to $<10 \mathrm{~g}$ for women and $>0$ to $<20 \mathrm{~g}$ for men to classify "moderate drinking" and $\geq 10 \mathrm{~g} /$ day for women and $\geq 20 \mathrm{~g} /$ day for men to classify "risky drinking". For measurement of the combined use of psychotropic drugs and alcohol we chose the categories "daily drinking"and "daily risky drinking" as this offers the strongest probability that both substances are taken simultaneously.

\section{Co-variables}

As co-variables we included sex, age group (60-69 and 70-79 years), social status according to a total score of a composite social status index [20] (lower, middle, upper), living alone (only one person living in a household), and urbanity (rural: <5000; small city: $5000-<20.000$; medium sized city: $20.000-<100.000$; large city: 100.000 and more residents). To determine region of residence we divided Germany into three commonly described geographical areas, each including several federal states: Northern Germany (Berlin, Brandenburg, Bremen, Hamburg, Lower Saxony, Mecklenburg-West Pomerania, and Schleswig-Holstein); Central Germany (Hesse, North Rhine-Westphalia, Saxony, Saxony-Anhalt, and Thuringia) and Southern Germany (Baden-Württemberg, Bavaria, Rhineland-Palatinate and Saarland). The following health-related co-variables were included: Self-assessed health status dichotomized as "better" (very good or good) and "worse" (moderate, bad, and very bad), having an officially certified disability (yes, no) and exposure to polypharmacy (five or more different products, prescribed and/or OTC within the past seven days, excluding psychotropic drugs). 


\section{Statistical analyses}

To generate population representative prevalence rates of psychotropic substance use in trend analyses a weighting factor was introduced. This served the correction of any deviations in the samples from population structure regarding age, sex, region of residence, municipality size, nationality, and educational level in comparison to the German population of the 31th December 2010 [15]. Re-participation probability of GNHIES98 participants was also included for calculation of the weighting factor. Characteristics of the population were analyzed via descriptive statistics. For the prevalence of psychotropic drug use and alcohol consumption, we calculated the absolute changes in percentage points (\%) and 95\% Confidence Intervals (95\% CIs) between surveys, both unadjusted and adjusted for co-variables. The adjusted changes in percentage points were derived from the predictive margins calculated from a logistic regression model [21, 22]. First-order interactions between the survey year and the co-variates were tested and included in the model if $p<0.10$. The predictive margins were calculated as the adjusted probabilities predicted by the model, averaged over all subjects in the model and assuming that the co-variable distribution in GNHIES98 and DEGS1 was identical. The standard errors and correlation of the predictive margins were approximated by the SAS LSMEANS statement and used in the calculation of the $95 \%$ CIs for the adjusted changes in percentage points. SAS 9.4 survey procedures for complex samples (SAS Institute Inc., Cary, NC) or SPSS complex samples module were used for statistical analyses. A probability level for statistically significant group differences was considered at $p<0.05$ based on two-sided tests.

\section{Results}

\section{Characteristics of study-populations}

There were no significant differences between the GNHIES98 and the DEGS1 population concerning socio-demographics (age, sex, urbanity, regions of residence, and social status) as well as the proportion of people living alone or having an officially certified disability (Table 1). Significant differences between the two survey-populations were found for "self-assessed health status" and "polypharmacy". More people rated their health as better in 2008-11 than in 1997-99. Contrarily, more people in 2008-11 used polypharmacy (Table 1).

\section{Changes in psychotropic drug use, alcohol consumption and combined use of both substances}

Table 2 depicts the changes in psychotropic drug use and alcohol consumption from 1997-99 to 2008-11 adjusted for sex, age group, region of residence, community size, social status, polypharmacy, living alone and having a recognized disability. In the models self-assessed health status was not included as an adjusting factor as it correlates to a large extend with polypharmacy. Repeated analyses with self-assessed health status replacing polypharmacy in models showed no significant changes.

After adjustments no changes over time in the use of overall synthetic or overall phytoceutical psychotropic drugs were found. In all categories of alcohol consumption we observed rising prevalence rates, but they were only significant for daily (adjusted change: $+9.6 \%, p$ $<.0001$ ) and moderate drinking (adjusted change: $+8.9 \% p-<.0001)$. Combined use of psychotropic drugs and daily or daily risky alcohol consumption remained unchanged (Table 2).

\section{Changes in the use of specific psychotropic drug groups}

Table 3 presents the changes in the use of specific groups and subgroups of psychotropic drugs between the surveys of 1997-99 and 2008-11. Prevalence of overall anti-depressants use $(6.4 \%$ vs. $7.9 \%)$ has not changed but we found significant changes in the following subgroups: The use of the phytoceutical antidepressant St. John's wort declined (adjusted change: $-5.0 \%, p=0.001)$ and the use of synthetical antidepressants increased (adjusted change: $+6.0 \%, p=0.001$ ). Among synthetical antidepressants we observed a significant rise in the use of selective serotonin reuptake inhibitors (SSRIs) (adjusted change: $+4.1 \%, p=<0.001$ ). Prevalence in the use of hypnotics \& sedatives (3.6\% vs. $3.3 \%$ ) or overall benzodiazepines \& benzodiazepinerelated drugs (Z-drugs) $(3.9 \%$ vs. $2.4 \%)$ remained unchanged. However, looking at benzodiazepine and Zdrug use separately, we found a significant decline in the use of benzodiazepines (adjusted change: $-3.4 \%, p$ $=0.024)$ and a significant rise in the use of Z-drugs (adjusted change: $+1.3 \%, p=<0.001$ ). Further, we observed significant rises in the use of overall anti-dementia drugs (adjusted change: $+3.2 \%, p=0.001$ ) - especially Ginkgo biloba (adjusted change: $+2.4 \%, p=0.001$ ) -, narcotic analgesics (N02A) (adjusted change: $+3.9 \%, p=$ 0.026 ), and anti-epileptics (adjusted change: $+3.6 \%, p=$ $<0.001)$. There were no significant changes in the use of anti-parkinson drugs (1.1\% vs. $1.2 \%)$ and anxiolytics $(2.4 \%$ vs. $2.2 \%$ ) within the observation period (Table 3 ).

\section{Changes in long-term use of psychotropic drugs}

Figure 1 depicts changes in prevalence of long-term use for some selected psychotropic drugs between the surveys of 1997-99 and 2008-11. Long-term use of opioid analgesics $(1.0 \%$ vs. $2.2 \%, p=0.045)$ was more than twice as high and long-term use of benzodiazepines $(2.0 \%$ vs. $1.0 \%, p=0.059)$ was halved in 2008-11. Long-term use of synthetical anti-depressants $(3.1 \%$ vs. $5.9 \%, p=0.002)$ 
Table 1 Descriptive characteristics of study populations aged 60-79 years. National Health Interview and Examination Surveys GNHIES98 (1997-99) and DEGS1 (2008-11)

\begin{tabular}{|c|c|c|c|c|c|c|c|c|c|}
\hline & \multicolumn{4}{|c|}{ GNHIES98 $(N=1606)$} & \multicolumn{4}{|c|}{$\operatorname{DEGS1}^{\mathrm{a}}(N=2501)$} & \multirow[t]{2}{*}{$P$ value } \\
\hline & $n$ & $\%$ & \multicolumn{2}{|l|}{$95 \%$ C } & $n$ & $\%$ & \multicolumn{2}{|c|}{$95 \% \mathrm{Cl}$} & \\
\hline \multicolumn{10}{|l|}{ Sex } \\
\hline Men & 727 & 47.0 & 44.7 & 49.3 & 1227 & 46.9 & 44.5 & 49.3 & \multirow[t]{2}{*}{.962} \\
\hline Women & 879 & 53.0 & 50.7 & 55.3 & 1274 & 53.1 & 50.7 & 55.5 & \\
\hline \multicolumn{10}{|l|}{ Age groups } \\
\hline $60-69$ years & 1031 & 52.5 & 49.9 & 55.1 & 1393 & 52.6 & 50.6 & 54.5 & \multirow[t]{2}{*}{.970} \\
\hline 70-79 years & 575 & 47.5 & 44.9 & 50.1 & 1108 & 47.4 & 45.5 & 49.4 & \\
\hline \multicolumn{10}{|l|}{ Living alone } \\
\hline Yes & 355 & 24.2 & 21.0 & 27.7 & 506 & 21.3 & 19.2 & 23.6 & \multirow[t]{2}{*}{.084} \\
\hline No & 1174 & 75.8 & 72.3 & 79.0 & 1983 & 78.7 & 76.4 & 80.8 & \\
\hline \multicolumn{10}{|l|}{ Urbanity $^{\mathrm{b}}$} \\
\hline Rural & 382 & 19.9 & 13.2 & 29.0 & 428 & 16.3 & 11.0 & 23.6 & \multirow[t]{4}{*}{.113} \\
\hline Small city & 333 & 18.9 & 12.4 & 27.8 & 586 & 25.6 & 19.0 & 33.6 & \\
\hline Medium sized city & 406 & 28.1 & 20.0 & 37.9 & 733 & 27.8 & 21.2 & 35.6 & \\
\hline Large city & 485 & 33.1 & 24.1 & 43.4 & 754 & 30.2 & 23.3 & 38.2 & \\
\hline \multicolumn{10}{|l|}{ Region of residence ${ }^{c}$} \\
\hline Northern Germany & 375 & 26.0 & 18.0 & 35.9 & 641 & 25.6 & 19.1 & 33.5 & \multirow[t]{3}{*}{.979} \\
\hline Central Germany & 781 & 40.7 & 31.5 & 50.7 & 1137 & 41.4 & 33.6 & 49.6 & \\
\hline Southern Germany & 450 & 33.3 & 24.3 & 43.7 & 723 & 33.0 & 25.7 & 41.2 & \\
\hline \multicolumn{10}{|l|}{ Social status } \\
\hline Lower & 374 & 26.1 & 22.8 & 29.6 & 436 & 24.1 & 21.2 & 27.3 & \multirow[t]{3}{*}{.393} \\
\hline Middle & 935 & 59.1 & 55.8 & 62.4 & 1489 & 59.3 & 56.3 & 62.3 & \\
\hline Upper & 233 & 14.8 & 12.1 & 17.9 & 562 & 16.5 & 14.6 & 18.7 & \\
\hline \multicolumn{10}{|c|}{ Officially certified disability } \\
\hline Yes & 371 & 26.0 & 23.3 & 29.0 & 647 & 29.1 & 26.4 & 31.9 & \multirow[t]{2}{*}{.079} \\
\hline No & 1168 & 74.0 & 71.0 & 76.7 & 1797 & 70.9 & 68.1 & 73.6 & \\
\hline \multicolumn{10}{|l|}{ Self-assed health status } \\
\hline Better & 781 & 47.8 & 44.4 & 51.1 & 1498 & 58.1 & 55.5 & 60.7 & \multirow[t]{2}{*}{$<.0001$} \\
\hline Worse & 825 & 52.2 & 48.9 & 55.6 & 985 & 41.9 & 39.3 & 44.5 & \\
\hline \multicolumn{10}{|l|}{ Polypharmacy ${ }^{\mathrm{d}}$} \\
\hline Yes & 466 & 30.0 & 27.1 & 33.0 & 993 & 38.8 & 36.5 & 41.2 & \multirow[t]{2}{*}{$<.0001$} \\
\hline No & 1140 & 70.0 & 67.0 & 72.9 & 1508 & 61.2 & 58.8 & 63.5 & \\
\hline
\end{tabular}

a Standardized to the population of 1.12 .2010

b Urbanity: Rural (<5000 residents), small city $(5000-<20.000)$, medium sized city $(20.000-<100.000)$, large city $(100.000$ and more residents)

c Regions: Northern Germany (federal states: Berlin, Brandenburg, Bremen, Hamburg, Lower Saxony, Mecklenburg-Vorpommern, Schleswig-Holstein), Central Germany (Hesse, North Rhine-Westphalia, Saxony, Saxony-Anhalt, Thuringia), Southern Germany (Baden-Württemberg, Bavaria,

Rhineland-Palatinate, Saarland)

d Polypharmacy: Use of five or more different prescribed and OTC drugs (excluding psychotropics) in the last seven days

Missing values: Living alone (GNHIES98 $n=77$, DEGS1 $n=12)$, social status $(64,14)$, officially certified disability $(67,57)$, self-assed health status $(0,18)$

Figures in bold denote statistical significance

increased significantly while long-term use of phytoceutical anti-depressants (St. John's wort) decreased significantly $(2.0 \%$ vs. $0.5 \%, p=<0.001)$ (Fig. 1$)$.

\section{Changes in psychotropic substance use according to socio-economic and health-related factors}

Psychotropic drug use and risky alcohol consumption among elderly participants of the surveys of 1997-99 and 2008-11 differentiated according to sex, social status and self-assessed health status are presented in Figs. 2a and b. Among people with a worse health status overall psychotropic drug use increased from $26.8 \%$ to $32.5 \%$ (Fig. 2a) $(p=0.024)$ and the use of opioid analgesics rose from $4.4 \%$ to $8.1 \%$ (Fig. $2 b)(p=0.004)$. Further, among people with a lower social status the use of opioid analgesics increased from $2.9 \%$ to $7.3 \%$ (Fig. 2b) 
Table 2 Changes in the prevalence of psychotropic drug use and alcohol consumption among adults aged 60-79 years in Germany. National Health Interview and Examination Surveys GNHIES98 (1997-99) and DEGS1 (2008-11)

\begin{tabular}{|c|c|c|c|c|c|c|c|c|c|c|c|c|c|c|c|c|}
\hline \multirow[b]{3}{*}{$\begin{array}{l}\text { All psychotropic drugs } \\
\text { (synthetics \& phytoceuticals) }\end{array}$} & \multicolumn{4}{|c|}{ GNHIES98 ${ }^{a}$} & \multicolumn{4}{|c|}{ DEGS1 $1^{a}$} & \multicolumn{8}{|c|}{ Change in \% (GNHIES98-DEGS1) } \\
\hline & \multirow{2}{*}{$\begin{array}{l}n \\
313\end{array}$} & \multirow{2}{*}{$\begin{array}{l}\% \\
20.5\end{array}$} & \multicolumn{2}{|c|}{$95 \% \mathrm{Cl}$} & \multirow{2}{*}{$\begin{array}{l}n \\
518\end{array}$} & \multirow{2}{*}{$\begin{array}{l}\% \\
21.4\end{array}$} & \multicolumn{2}{|c|}{$95 \% \mathrm{Cl}$} & \multirow{2}{*}{$\begin{array}{l}\text { Unadjusted }^{\mathrm{a}} \\
1.0\end{array}$} & \multicolumn{2}{|c|}{$95 \% \mathrm{Cl}$} & \multirow{2}{*}{$\begin{array}{l}p \text { value } \\
.554\end{array}$} & \multirow{2}{*}{$\begin{array}{l}\text { Adjusted }^{a, b} \\
-0.3\end{array}$} & \multicolumn{2}{|c|}{$95 \% \mathrm{Cl}$} & \multirow{2}{*}{$\frac{p \text { value }}{0.897}$} \\
\hline & & & 18.2 & 22.9 & & & 19.3 & 23.7 & & -2.2 & 4.1 & & & -5.4 & 4.8 & \\
\hline All phytoceuticals & 107 & 6.7 & 5.4 & 8.3 & 158 & 6.5 & 5.4 & 7.8 & -0.2 & -1.9 & 1.5 & .827 & -0.1 & -2.3 & 2.2 & 0.956 \\
\hline All synthetics & 223 & 14.6 & 12.6 & 16.9 & 404 & 16.9 & 14.9 & 19.1 & 2.3 & -0.8 & 5.3 & .145 & 1.5 & -4.3 & 7.2 & 0.622 \\
\hline $\begin{array}{l}\text { Weekly alcohol use } \\
\text { (at least once a week) }\end{array}$ & 739 & 48.8 & 45.5 & 52.2 & 1295 & 51.0 & 48.1 & 53.9 & 2.1 & -2.0 & 6.2 & .305 & 4.0 & -3.8 & 11.8 & 0.319 \\
\hline $\begin{array}{l}\text { Daily alcohol use } \\
\text { (at least once a day) }\end{array}$ & 185 & 13.2 & 11.1 & 15.5 & 468 & 18.4 & 16.3 & 20.7 & 5.2 & 2.4 & 8.1 & .001 & 9.6 & 5.7 & 13.6 & $<.001$ \\
\hline Moderate drinking $^{c}$ & 919 & 58.0 & 54.6 & 61.3 & 1659 & 66.9 & 64.1 & 69.5 & 8.9 & 4.9 & 13.0 & $<.001$ & 8.9 & 4.6 & 13.1 & $<.001$ \\
\hline Risky drinking ${ }^{d}$ & 240 & 16.6 & 14.2 & 19.4 & 459 & 17.0 & 14.9 & 19.2 & 0.3 & -2.7 & 3.3 & .836 & 0.4 & -2.0 & 2.9 & 0.724 \\
\hline $\begin{array}{l}\text { Psychotropic drugs } \\
\text { + daily drinking }\end{array}$ & 25 & 1.8 & 1.2 & 2.7 & 76 & 2.7 & 2.0 & 3.7 & 0.9 & -0.2 & 2.1 & .122 & 1.3 & -0.3 & 2.8 & 0.105 \\
\hline $\begin{array}{l}\text { Psychotropic drugs } \\
+ \text { daily risky drinking }\end{array}$ & 20 & 1.5 & .9 & 2.4 & 59 & 2.1 & 1.5 & 2.9 & 0.6 & -0.4 & 1.6 & .274 & 0.7 & -0.5 & 1.9 & 0.258 \\
\hline
\end{tabular}

a Standardized to the population of 31.12 .2010

${ }^{b}$ Adjusted for sex, age group, region, community size, social status, polypharmacy, living alone, recognized disability

c Moderate drinking: average daily consumption of alcohol between $>0$ and $<10 \mathrm{~g}$ for women, and between $>0$ and $<20 \mathrm{~g}$ for men

${ }^{d}$ Risky drinking: average daily consumption of alcohol $\geq 10 \mathrm{~g}$ for women, and $\geq 20 \mathrm{~g}$ for men

Figures in bold denote statistical significance

$(p=0.018)$ and among men the use of benzodiazepines decreased from $3.3 \%$ to $1.4 \%$ (Fig. $2 \mathrm{~b})(p=0.023)$.

Figure $2 \mathrm{a}$ and $\mathrm{b}$ show that for the use of antidepressants, benzodiazepines and opioids gender gaps were widening and narrowing for risky drinking. Gaps between lower and upper social status were widening concerning the use of all groups of psychotropic drugs and narrowing for risky drinking. Gaps were also widening between those with a better and a worse health status for the use of overall psychotropic drugs, antidepressants, and opioids. Between those with a better and a worse health status gaps were also widening concerning risky drinking. This was due to fewer people with a worse health status and more people with a better health status engaging in risky drinking.

\section{Discussion}

\section{Main findings}

Overall psychotropic drug use remained stable while daily and moderate alcohol drinking increased between the two surveys of 1997-99 and 2008-11. Changes were observed for specific psychotropic drug groups and subgroups. Significant increases were found in the use of synthetical antidepressants (particularly SSRIs), Z-drugs, overall anti-dementia drugs (especially Ginkgo biloba), opioid analgesics, and anti-epileptics. The use of the phytoceutical antidepressant St. John's wort and of benzodiazepines declined significantly. Significant rises were observed in the long-term use of opioid analgesics and synthetical anti-depressants, while the long-term use of benzodiazepines and St. John's wort decreased significantly. Among people with a worse health status the use of overall psychotropic drugs and opioid analgesics increased significantly. Among those with a lower social status the use of opioid analgesics increased significantly while among men the use of benzodiazepines decreased significantly.

\section{Comparison to other studies}

A comparison of prevalence rates has been described in our previous study [11]. In the present work we compared changes over time and direction of changes and found predominantly similar tendencies in psychotropic drug use in western countries. Prevalence rates of psychotropic drug use might vary between studies due to differences in observation periods, years of study conduction, settings, age groups, and drugs included. Differences in psychotropic drug use between countries could be due to differences in health care- and reimbursement systems, in understanding of psychiatric problems, cultural attitudes or traditions (i.e. Germany has a long tradition of phytoceutical therapies) $[8,23]$.

\section{Changes in overall psychotropic drug use and alcohol consumption}

In our study overall psychotropic drug use remained unchanged between the two surveys of 1997-99 and 2008-11. A Finnish study [24] also reported unchanged 
Table 3 Changes in the prevalence of the use of specific psychotropic drug groups among adults aged 60-79 years in Germany. National Health Interview and Examination Surveys GNHIES98 (1997-99) and DEGS1 (2008-11)

\begin{tabular}{|c|c|c|c|c|c|c|c|c|c|c|c|c|c|c|c|c|}
\hline \multirow{3}{*}{$\begin{array}{l}\text { 1. All anti-depressants (St. John's wort } \\
\text { and all synthetical antidepressants) }\end{array}$} & \multicolumn{4}{|c|}{ GNHIES98 ${ }^{a}$} & \multicolumn{4}{|c|}{ DEGS1 ${ }^{a}$} & \multicolumn{8}{|c|}{ Change in \% (GNHIES98-DEGS1) } \\
\hline & \multirow{2}{*}{$\begin{array}{l}n \\
96\end{array}$} & \multirow{2}{*}{$\begin{array}{l}\% \\
6.4\end{array}$} & \multicolumn{2}{|c|}{$95 \% \mathrm{Cl}$} & \multirow{2}{*}{$\begin{array}{l}n \\
173\end{array}$} & \multirow{2}{*}{$\begin{array}{l}\% \\
7.9\end{array}$} & \multicolumn{2}{|c|}{$95 \% \mathrm{Cl}$} & \multirow{2}{*}{$\begin{array}{l}\text { Unadjusted }^{\mathrm{a}} \\
1.4\end{array}$} & \multicolumn{2}{|c|}{$95 \% \mathrm{Cl}$} & \multirow{2}{*}{$\begin{array}{l}p \text { value } \\
.157\end{array}$} & \multirow{2}{*}{$\begin{array}{l}\text { Adjusted }^{\mathrm{a}, \mathrm{b}} \\
1.7\end{array}$} & \multicolumn{2}{|c|}{$95 \% \mathrm{Cl}$} & \multirow{2}{*}{$\begin{array}{l}p \text { value } \\
0.343\end{array}$} \\
\hline & & & 5.2 & 7.9 & & & 6.5 & 9.5 & & -0.6 & 3.4 & & & -1.8 & 5.2 & \\
\hline 1.1 St. John's wort (N06AP) & 47 & 2.9 & 2.1 & 3.9 & 27 & 1.1 & 0.8 & 1.7 & -1.7 & -2.7 & -0.8 & $<.001$ & -5.0 & -7.9 & -2.0 & 0.001 \\
\hline 1.2 All synthetical antidepressants & 54 & 3.9 & 2.9 & 5.2 & 151 & 6.9 & 5.5 & 8.5 & 3.0 & 1.2 & 4.8 & .001 & 6.0 & 2.5 & 9.4 & 0.001 \\
\hline 1.2.1. $\mathrm{NSMRIS}^{\complement}(\mathrm{N} 06 \mathrm{AA})$ & 45 & 3.6 & 2.6 & 4.8 & 80 & 3.8 & 2.8 & 5.2 & 0.3 & -1.3 & 1.8 & .741 & 0.4 & -2.7 & 3.5 & 0.806 \\
\hline 1.2.2. $\mathrm{SSRIS}^{\mathrm{d}}(\mathrm{N} 06 \mathrm{AB})$ & 3 & 0.3 & 0.1 & 1.0 & 47 & 2.0 & 1.4 & 2.7 & 1.7 & 1.0 & 2.4 & .001 & 4.1 & 2.4 & 5.8 & $<.0001$ \\
\hline $\begin{array}{l}\text { 2. All hypnotics \& sedatives (synth., } \\
\text { antihistamines and phytoceuticals) }\end{array}$ & 62 & 3.6 & 2.8 & 4.8 & 98 & 3.3 & 2.6 & 4.3 & -0.3 & -1.6 & 1.0 & .644 & -1.3 & -3.5 & 0.9 & 0.234 \\
\hline $\begin{array}{l}2.1 \text { All synth. (N05C) and } \\
\text { antihistamines (N05CM) }\end{array}$ & 31 & 1.6 & 1.1 & 2.4 & 52 & 1.6 & 1.1 & 2.2 & 0.0 & -0.9 & 0.8 & .921 & -0.1 & -1.7 & 1.4 & 0.861 \\
\hline 2.1.1. Hypnotics \& sedatives (N05C) & 31 & 1.6 & 1.1 & 2.4 & 42 & 1.3 & 0.9 & 1.9 & -0.3 & -1.1 & 0.5 & .430 & -0.6 & -2.2 & 0.9 & 0.412 \\
\hline 2.2. All phytoceuticals & 32 & 2.1 & 1.4 & 3.0 & 51 & 1.9 & 1.3 & 2.6 & -0.2 & -1.2 & 0.8 & .703 & -0.6 & -1.9 & 0.6 & 0.307 \\
\hline 2.2.1. Valerian (N05CP) & 28 & 1.8 & 1.2 & 2.7 & 42 & 1.5 & 1.0 & 2.1 & -0.3 & -1.2 & 0.6 & .453 & -0.5 & -1.7 & 0.7 & 0.408 \\
\hline $\begin{array}{l}\text { 3. Benzodiazepines and } \\
\text { benzodiazepine-related drugs }\end{array}$ & 64 & 3.9 & 2.9 & 5.2 & 84 & 3.3 & 2.4 & 4.4 & -0.6 & -2.1 & 0.8 & .389 & -2.0 & -5.0 & 0.9 & 0.176 \\
\hline $\begin{array}{l}\text { 3.1. Benzodiazepines } \\
\text { (N05BA, N05CD, N03AE01) }\end{array}$ & 57 & 3.7 & 2.8 & 5.0 & 57 & 2.5 & 1.8 & 3.5 & -1.2 & -2.6 & 0.2 & .081 & -3.4 & -6.3 & -0.4 & 0.024 \\
\hline $\begin{array}{l}\text { 3.2. Benzodiazepine-related } \\
\text { drugs (Z-drugs) (N05CF) }\end{array}$ & 8 & 0.2 & 0.1 & 0.5 & 28 & 0.8 & 0.5 & 1.3 & 0.6 & 0.2 & 1.0 & .003 & 1.3 & 0.6 & 2.1 & $<0.001$ \\
\hline $\begin{array}{l}\text { 4. All anti-dementia drugs } \\
\text { incl. ginkgo biloba }\end{array}$ & 34 & 2.2 & 1.4 & 3.4 & 97 & 4.2 & 3.3 & 5.4 & 2.0 & 0.7 & 3.3 & .005 & 3.2 & 1.3 & 5.1 & 0.001 \\
\hline 4.1. Ginkgo biloba (N06DP01) & 34 & 2.2 & 1.4 & 3.4 & 88 & 3.8 & 2.9 & 4.8 & 1.6 & 0.3 & 2.8 & .022 & 2.4 & 1.0 & 3.8 & 0.001 \\
\hline 5. Narcotic analgesics (N02A) & 39 & 3.0 & 2.1 & 4.2 & 96 & 4.1 & 3.2 & 5.3 & 1.2 & -0.3 & 2.6 & .121 & 3.9 & 0.5 & 7.3 & 0.026 \\
\hline 6. Anti-epileptics (N03) & 14 & 1.0 & 0.5 & 1.7 & 63 & 2.3 & 1.7 & 3.3 & 1.4 & 0.4 & 2.3 & .008 & 3.6 & 1.7 & 5.5 & $<0.001$ \\
\hline 7. Antiparkinson drugs (N04) & 19 & 1.1 & .7 & 1.8 & 32 & 1.2 & 0.7 & 2.0 & 0.1 & -0.7 & 0.9 & .806 & -0.1 & -1.4 & 1.3 & 0.934 \\
\hline 8. Anxiolytics (N05B) & 34 & 2.4 & 1.6 & 3.5 & 48 & 2.2 & 1.5 & 3.1 & -0.2 & -1.4 & 1.0 & .751 & -1.2 & -3.2 & 0.9 & 0.268 \\
\hline
\end{tabular}

${ }^{a}$ standardized to the population of 31.12 .2010

b adjusted for sex, age group, region, community size, social status, polypharmacy, living alone, recognized disability

cNon-Selective Monoamine Reuptake Inhibitors

${ }^{\mathrm{d}}$ Selective Serotonin Reuptake Inhibitors

Figures in bold denote statistical significance

prevalences of overall psychotropic drug use between 1990-91 and 1998-99 and a Swedish study [25] observed unchanged prevalences among cognitive intact elderly, but significant rises among cognitive impaired elderly between 1987 and 2007. Contrarily, significant increases in overall psychotropic drug use were reported by an US [26] and a Spanish study [27]. However, the US-study included only a three year observation period (1999-2002) which might cover a period with a higher increase and the Spanish study (1993 and 2003) involved older age groups $(65+)$. Further, comparisons between countries might be difficult for the above described reasons.

In our study both, daily and moderate alcohol drinking increased significantly. Other studies described rises in risky drinking among the elderly [28, 29]. As in our analyses, higher prevalence rates of alcohol consumption were found among men [28-30] and narrowing gender gaps in the US, Australia, and European countries were described by a literature review of Keyes et al. [30] and a Swedish study [31]. Consistent with our findings, risky drinking was associated with a higher social status in some studies [32, 33]. In contrast to our results, risky drinking was associated with lower social class in an inner city study in the UK [34].

The growing alcohol consume among older people could be due to more healthy life years and improved incomes of the elderly. The rising alcohol consume in women could be due to a greater social acceptance and more financial independence [35]. Further, cohort effects and the impact of socio-historical contexts could influence drinking behavior [29].

\section{Changes in prevalence of specific psychotropic drug groups and subgroups}

The significant increase in the use of synthetical antidepressants among the elderly, particularly of SSRIs, is also 


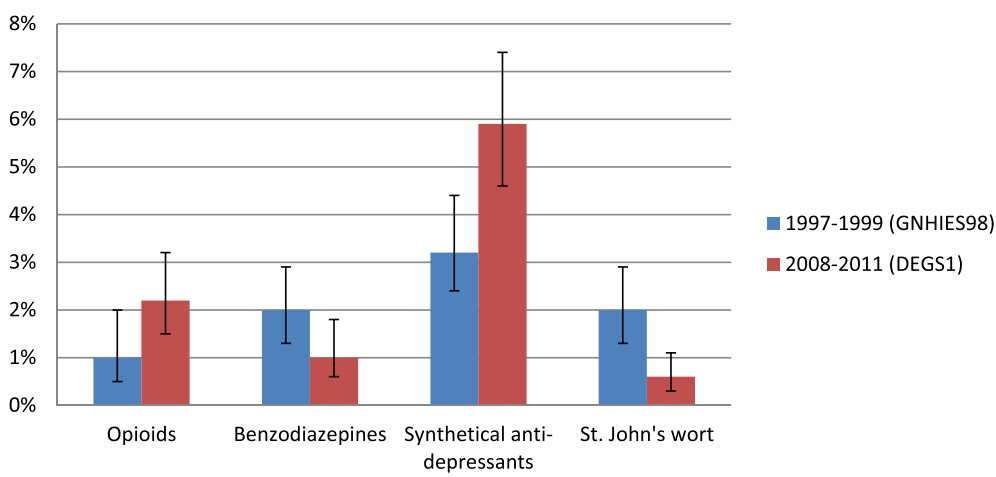

Fig. 1 Prevalence of long-term psychotropic drug use among adults aged 60-79 years in Germany. National Health Interview and Examination Surveys GNHIES98 (1997-99) and DEGS1 (2008-11)

confirmed by other population based studies [24-26, $36,37]$ as well as by studies based on dispensing-data $[38,39]$. In our analysis the use of phytoceutical antidepressants (St. John's wort) decreased significantly but international literature on changes/trends in the use of St. John's wort is scarce. An American study on changes in sales of supplements [40] reported a peak in sales of St. John's wort in 1998 followed by a decline until 2004 and then followed by stable sales until 2006. Further, similar as our study, other studies in Europe and the US observed a significant rise in the use of opioid analgesics [41-43], and Z-drugs [44] and a decrease in the use of benzodiazepines [44-46] among older people. In the present analyses we observed an increased use of overall anti-dementia drugs. This tendency was confirmed by a population-based Spanish study [47] and a Swedish study among residents of geriatric care [48]. The significant increase in the use of phytoceutical anti-dementia (Ginkgo biloba) in our study was also reported by an American study (1994-1999) [49], while a later conducted American study (1998-2002) [50] found a decrease in the use of Ginkgo biloba. In line with our study too, significant increases in the use of anti-epileptics were described by a Danish [51] and a Canadian [52] study as well as by a study comparing health record data of Spain, Denmark, Netherlands, the UK and Germany [53].

Rises in the use of synthetic antidepressants, antidementia, opioid analgesics and anti-epileptics might reflect a more efficient diagnosing, greater choice of medicines available, improved medical care for the elderly and improved adherence to guidelines. A German adaptation of the guidelines on Potential Inadequate Medication (PIM) for the elderly $[54,55]$ recommends for example to prescribe specific SSRIs (and other medicines) instead of a number of classical antidepressants of the ATC class N06AA, which could explain the significant rise in SSRI use among the elderly. The reasons for the decrease in the use of phytoceutical antidepressants (St. John's wort) and the shift towards new synthetical antidepressants are unclear as studies, e.g. a meta-analysis of Cui (2016) [56] came to the result that for the treatment of mild and moderate depression St. John's wort is equally effective as SSRIs and has fewer side-effects. The decrease in benzodiazepine use and a shift towards using more Z-drugs might reflect a growing concern about the side effects of benzodiazepines and a greater adherence to guidelines advising to prescribed Z-drugs instead of long-lasting benzodiazepines to older adults [54, 55]. Further, the guidelines recommend that older people use valerian (and other substances) instead of medium- and short-lasting benzodiazepines [54, 55]. However, a decrease in the use of valerian was found in our study. The increased use of opioid analgesics among older adults might be beneficial for pain reduction and improvement of physical function, but can also impair mental health functioning [57] and lead to falls and fractures [58].

\section{Changes in long-term-use of psychotropic drugs}

As in our study, increases in long-term antidepressants use were also found for example in Finland [24] and the US [59]. Also comparable to our study, the long-term use of benzodiazepines decreased in a Finnish study [24]. A Dutch study [60] reported a decline in moderate duration of benzodiazepine use. Moderate duration of use was defined as $\geq 1$ month $-\leq 1$ year while long-term use was defined as $\geq 3$ months in our study. Similar to other studies [43, 61, 62] we observed a significant rise in the long-term use of opioid analgesics among the elderly.

The increase in long-term use of synthetical antidepressants could be due to a better tolerability of new substances and a rise of treatment in accordance with medical guidelines. Increased use and long-term use of opioid analgesics could be due to changes in drug politics and due to rising diagnosis of pain [61, 62]. It might reflect a more adequate treatment of pain among older 

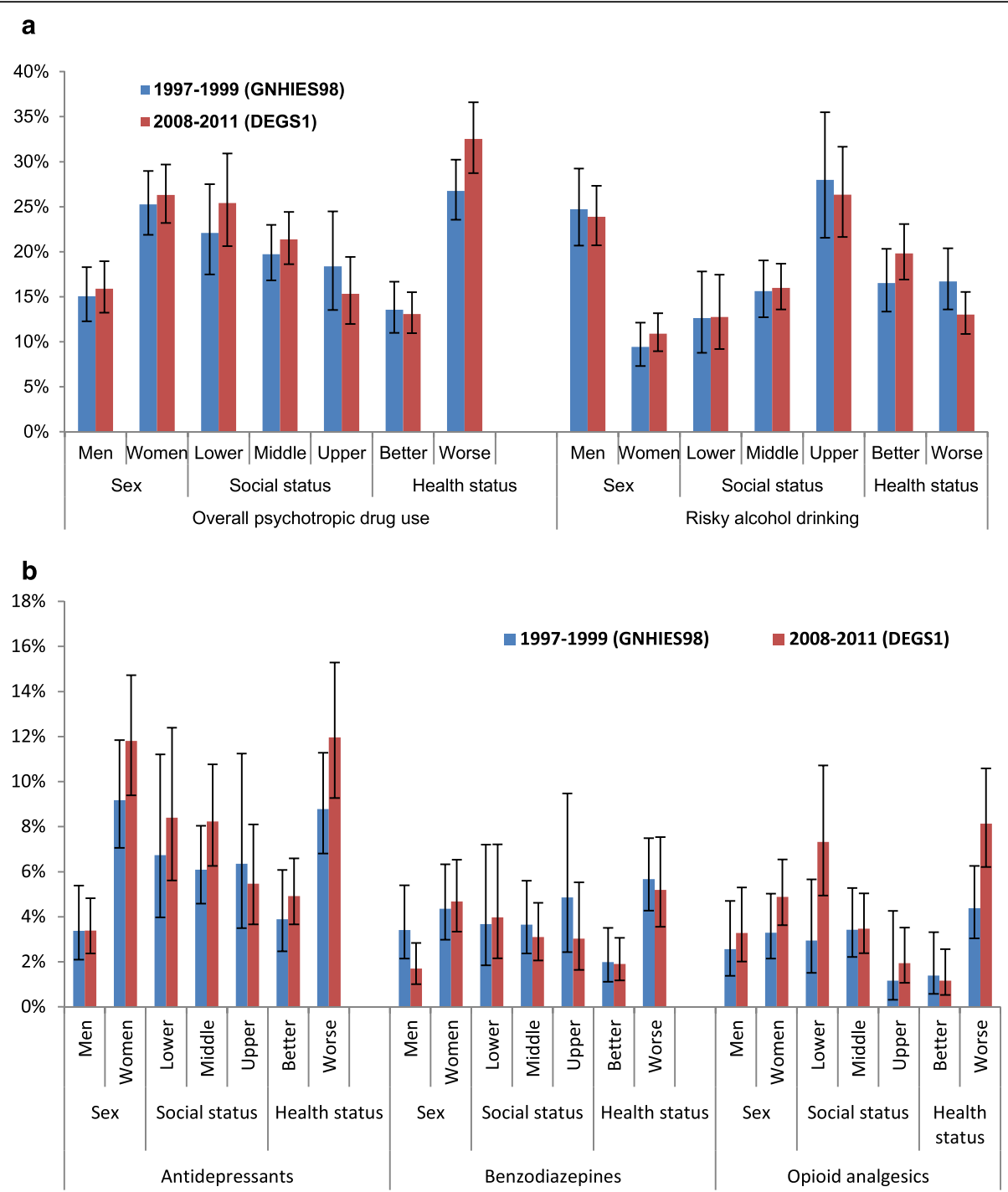

Fig. 2 a. Overall psychotropic drug use and risky drinking among adults aged 60-79 years in Germany by sex, social status and self-assessed health status. National Health Interview and Examination Surveys GNHIES98 (1997-99) and DEGS1 (2008-11). Risky drinking: Average daily consumption of alcohol $\geq 10 \mathrm{~g}$ for women, and $\geq 20 \mathrm{~g}$ for men. $\mathbf{b}$ : Use of antidepressants, benzodiazepines and opioid analgesics among adults aged 60-79 years in Germany by sex, social status and self-assessed health status. National Health Interview and Examination Surveys GNHIES98 (1997-99) and DEGS1 (2008-11). Antidepressants: Synthetics (N06A) and St. John's wort (N06AP01). Benzodiazepines: N05BA, N05CD, N03AE01 and N05CF. Opioid analgesics: N02A

adults, although benefits and risks of long-term opioid use are discussed controversial in literature $[4,6,43,57]$.

\section{Changes in psychotropic drug use according to socio-demographic and health-related factors}

In our analyses people with a lower social status were more likely to use opioids and those with a worse health status more likely to use overall psychotropic drugs and opioids, with gaps widening compared to their counterparts. A study comparing data from Canada, Albania, Colombia and Brazil [63] found a higher psychotropic drug use among people with a lower social status in Canada but not in Latin America. In Albania a lower social status was a predictor for higher use of anxiolytics, sedatives and hypnotics while antidepressants use was generally low [63]. In a Scottish study [41] use of strong opioids (classified according to the British National Formulary 2012) increased significantly and was associated with a lower social status and polypharmacy. In a Dutch study [60] benzodiazepine use remained stable between 1992 and 2002 and was associated with female sex, lower social status and a worse health status. Significant increases of psychotropic drug use among people with a worse health status were also reported by a Spanish study [36], while a Brazilian study [64] observed a significant rise in the use of antidepressants, which was 
associated with increased income and reasonable selfassed health status. Further, we found a decreasing benzodiazepine use in men which was confirmed by a Dutch study [60]. Our analyses showed a higher prevalence of psychotropic drug use in women and a growing gender gap over time which was also reported by other studies [24, 38, 43].

Differences in psychotropic drug use according to social status reflect the general social inequality of health and a higher use of psychotropic drugs among people with a worse health status was expectable. Reasons for older women's higher consumption of psychotropic drugs might be rooted in different perceptions of mental or physical health [65], different patterns concerning the use of health-services [66], health professionals being more likely to prescribe psychotropic drugs to women [65], more inappropriate prescribing for women [66, 67] or differences in symptom patterns leading to underdiagnosing in men [68].

\section{Strengths and limitations}

One of the strengths of our study is the large sample size of nation-wide and population based representative data. This allows generalization to the community dwelling population of Germany. Recall-bias concerning psychotropic drug use was minimized by limiting the observation window to 7 days prior to interview and by asking participants to bring along original packages of their medicines. Furthermore, recording all consumed medicines including privately prescribed, phytoceutical and OTC products, allowed us to analyse the "real" drug use among the community dwelling population. This is particularly relevant for the use of benzodiazepines as in Germany about $50 \%$ of benzodiazepine prescriptions are prescribed privately [7] and therefore are not recorded by health insurance data.

Limitations of our study include a selection bias as institutionalized people were excluded. Also, people with severe illnesses or cognitive impairments are underrepresented as they might not be able to come to the study centers. Further, the age limit of 79 years excludes those who might be mostly affected by medication use. An underestimation of psychotropic drug use among the elderly is therefore likely. It is also likely that we underestimated risky drinking as older people with severe alcohol problems might not come to examination sites.

\section{Conclusion}

Psychotropic drug use among the elderly remained stable at a high level in Germany. Changes in the use of some psychotropic drug subgroups as well as of alcohol consumption patterns have been observed with significant rises in the use of synthetical antidepressants, opioid analgesics, Z-drugs, anti-dementia drugs, antiepileptics, daily and moderate alcohol consumption. Female sex, lower social status and a worse health status were associated with psychotropic drug use in both surveys and gaps were growing compared to their counterparts. Rising alcohol consumption and rises in the use of potentially addictive drugs among the elderly are developments which could point towards a growing public health problem. Further studies are needed to evaluate health outcomes following changes in psychotropic substance use among the elderly.

\section{Abbreviations \\ ATC code: Anatomical therapeutic chemical code; CAPI: Computer assisted personal interview; Cl: Confidence interval; DEGS1: German health interview and examination survey for adults 2008-11, first wave; GNHIES98: German national health interview and examination survey 1997-99; NSMRI: Non- selective monoamine reuptake inhibitors; OTC: Over-the counter; PIM: Potential inadequate medication; RKI: Robert Koch Institute; SSRI: Selective serotonin reuptake inhibitors; Z-drugs: Benzodiazepine-related drugs}

\section{Acknowledgments}

We thank the survey participants for contributing towards our understanding of psychotropic substance use among older adults.

\section{Funding}

This work was supported by the Federal Ministry of Health and the Robert Koch Institute. GNHIES98 and DEGS1 were funded by the Federal Ministry of Health.

\section{Availability of data and material}

The authors confirm that some access restrictions apply to the data underlying the findings. The data set cannot be made publicly available because informed consent from study participants did not cover public deposition of data. However, the minimal data set underlying the findings is archived in the 'Health Monitoring' Research Data Centre at the Robert Koch Institute (RKI) and can be accessed by all interested researchers. On-site access to the data set is possible at the Secure Data Center of the RKI's 'Health Monitoring' Research Data Centre. Requests should be submitted to the 'Health Monitoring' Research Data Centre, Robert Koch Institute, Berlin, Germany (e-mail: fdz@rki.de).

\section{Authors' contribution}

IKW helped conceptualize the study, provided the literature review, interpreted the results and wrote the manuscript. YD helped conceptualize the study, conducted the statistical analyses, interpreted the results, contributed to literature review and reviewed the manuscript. HK generated the original idea, coordinated, conceptualized and conducted the project, provided specific knowledge and reviewed the manuscript. HK is the guarantor who takes the responsibility for the study. All authors read and approved the final manuscript.

\section{Competing interest}

The authors declare that they have no competing interest.

\section{Consent for publication \\ Not applicable.}

\section{Ethics approval and consent to participate}

Participants provided written informed consent prior to interview and examination in both studies. GNHIES98 was approved by the federal data protection officials and DEGS1 was approved by the Federal and State Commissioners for Data Protection and the Charité-Universitätsmedizin Berlin ethics committee (No. EA2/047/08).

\section{Publisher's Note}

Springer Nature remains neutral with regard to jurisdictional claims in published maps and institutional affiliations. 


\section{Received: 12 October 2016 Accepted: 4 March 2017} Published online: 09 March 2017

\section{References}

1. Pringle KE, Ahern FM, Heller DA, Gold CH, Brown TV. Potential for alcohol and prescription drug interactions in older people. J Am Geriatr Soc. 2005; 53:1930-36.

2. Trifiró G, Spina E. Age-related changes in pharmacodynamics: Focus on drugs acting on central nervous and cardiovascular systems. Curr Drug Metab. 2011;12:611-20

3. Coupland C, Dhiman P, Morriss R, Arthur A, Barton G, Hippisley-Cox J. Antidepressant use and risk of adverse outcomes in older people: population based cohort study. BMJ. 2011:343:d4551.

4. Chou R, Deyo R, Devine B, Hansen R, Sullivan S, Jarvik JG, et al. The Effectiveness and Risks of Long-Term Opioid Treatment of Chronic Pain. Evidence Report/Technology Assessment No. 218. (Prepared by the Pacific Northwest Evidence-based Practice Center under Contract No. 290-201200014-I.) AHRQ Publication No. 14-E005-EF. Rockville, MD: Agency for Healthcare Research and Quality. 2014. https://www.ncbi.nlm.nih.gov/books/ NBK258809/. Accessed 2 Aug 2016.

5. Moore AA, Whiteman EJ, Ward KT. Risks of combined alcohol/medication use in older adults. Am J Geriatr Pharmacother. 2007;5:64-74.

6. Häuser W, Bock F, Engeser P, Tölle T, Willweber-Strumpf A, Petzke F. Clinical practice guideline: Long-term opioid use in non-cancer pain. Dtsch Arzteb Int. 2014;111:732-40

7. Janhsen K, Roser P, Hoffmann K. The problems of long-term treatment with benzodiazepines and related substances. Dtsch Arztebl Int. 2015;112:1-7.

8. Hartel U, Volger E. Use and acceptance of classical natural and alternative medicine in Germany-findings of a representative population-based survey. Forsch Komplementarmed Klass Naturheilkd. 2004;11(6):327-34.

9. OECD. Health at a Glance: EUROPE 2014. How does Germany compare. 2014. https://www.oecd.org/els/health-systems/Health-at-a-Glance-EUROPE2014-Briefing-Note-GERMANY.pdf. Accessed 18 Jan 2017.

10. Burger M, Mensink GB. High alcohol consumption in Germany: results of the German National Health Interview and Examination Survey 1998. Public Health Nutr. 2004;7:879-84

11. Du Y, Wolf IK, Knopf H. Psychotropic drug use and alcohol consumption among older adults in Germany: results of the German Health Interview and Examination Survey for Adults 2008-2011. BMJ Open. 2016;6:e012182.

12. Scheidt-Nave C, Kamtsiuris P, Gosswald A, Hölling H, Lange M, Busch MA, et al. German health interview and examination survey for adults (DEGS) design, objectives and implementation of the first data collection wave. BMC Public Health. 2012;12:730.

13. Thefeld W, Stolzenberg H, Bellach B. Bundes-Gesundheits Survey: Response, Zusammensetzung der Teilnehmer und Non-Responder-Analyse (German National Health Interview and Examination Survey: response, composition of participants and analysis of non-respondents). Gesundheitswesen. 1999; 61:57-62.

14. Thefeld W, Stolzenberg H, Bellach BM. Bundes-Gesundheitssurvey: Response, Zusammensetzung der Teilnehmer und Non-Response-Analyse. [National health Survey: Response, composition of participants and non-responseanalysis]. Gesundheitsw. 1999;61:57-62.

15. Kamtsiuris $P$, Lange M, Hoffmann R, Schaffrath Rosario A, Dahm S, Kuhnert $R$, et al. Die erste Welle der Studie zur Gesundheit Erwachsener in Deutschland (DEGS1): Stichprobendesign, Response, Gewichtung und Repräsentativitat. [The first wave of the German Health Interview and Examination Survey for Adults (DEGS1): sample design, response, weighting and representativeness]. Bundesgesundheitsbl Gesundheitsforsch Gesundheitssch. 2013:56:620-30.

16. Gemeinsamer Bundesausschuss, [The Federal Joint Committee]. Arzneimittelrichtlinie [Pharmaceutical guideline]. https://www.g-ba.de/ informationen/richtlinien/3/. Accessed 28 Apr 2016.

17. van Broekhoven F, Kan CC, Zitman FG. Dependence potential of antidepressants compared to benzodiazepines. Prog Neuropsychopharmacol Biol Psychiatry. 2002;26:939-43.

18. Burger M, Mensink G, Bronstrup A, Thierfelder W, Pietrzik K. Alcohol consumption and its relation to cardiovascular risk factors in Germany. Eur J Clin Nutr. 2004:58:605-14.

19. Dawson DA. Defining risk drinking. Alcohol Res Health. 2011;34:144-56.
20. Lampert T, Kroll LE, Muters S, Stolzenberg H. Messung des soziookonomischen Status in der Studie "Gesundheit in Deutschland aktuell" (GEDA). [Measurement of the socioeconomic status within the German Health Update 2009 (GEDA)]. Bundesgesundheitsb Gesundheitsforsch Gesundheitssch. 2013;56:131-43.

21. Greenland S. Model-based estimation of relative risks and other epidemiologic measures in studies of common outcomes and in casecontrol studies. Am J Epidemiol. 2004;160:301-05.

22. Graubard BI, Korn EL. Predictive margins with survey data. Biometrics. 1999; 55:652-59.

23. Du Y, Wolf IK, Zhuang W, Bodemann S, Knoss W, Knopf H. Use of herbal medicinal products among children and adolescents in Germany. BMC Complement Altern Med. 2014;14:218.

24. Linjakumpu T, Hartikainen S, Klaukka T, Koponen H, Kivela SL, Isoaho R. Psychotropics among the home-dwelling elderly-increasing trends. Int Geriatr Psychiatry. 2002;17:874-83.

25. Craftman AG, Johnell K, Fastbom J, Westerbotn M, von Strauss E. Time trends in 20 years of medication use in older adults: Findings from three elderly cohorts in Stockholm. Sweden Arch Gerontol Geriatr. 2016;63:28-35.

26. Paulose-Ram R, Safran MA, Jonas BS, Gu Q, Orwig D. Trends in psychotropic medication use among U.S. adults. Pharmacoepidemiol Drug Saf. 2007:16:560-70.

27. Carrasco-Garrido P, Jimenez-Garcia R. stasio-Arbiza P, Ortega-Molina P, de Miguel AG. Psychotropics use in the Spanish elderly: predictors and evolution between years 1993 and 2003. Pharmacoepidemiol Drug Saf. 2007;16:449-57.

28. Sulander T, Helakorpi S, Rahkonen O, Nissinen A, Uutela A. Smoking and alcohol consumption among the elderly: Trends and associations, 19852001. Prev Med. 2004:39:413-18.

29. Wadd S, Papadopoulos C. Drinking behaviour and alcohol-related harm amongst older adults: analysis of existing UK datasets. BMC Res Notes. 2014;7:741.

30. Keyes K, Li G, Hasin D. Birth cohort effects and gender differences in alcohol epidemiology: a review and synthesis. Alcohol Clin Exp Res. 2011:35:2101-12.

31. Waern M, Marlow T, Morin J, Ostling S, Skoog I. Secular changes in at-risk drinking in Sweden: birth cohort comparisons in 75-year-old men and women 1976-2006. Age Ageing. 2014;43:228-34.

32. Merrick E, Horgan C, Hodgkin D, Garnick D, Houghton S, Panas L, et al. Unhealthy drinking patterns in older adults: prevalence and associated characteristics. J Am Geriatr Soc. 2008;56:214-23.

33. Castillo-Carniglia A, Kaufman JS, Pino P. Small area associations between social context and alcohol-attributable mortality in a middle income country. Drug Alcohol Depend. 2014;137:129-36.

34. Rao R, Schofield P, Ashworth M. Alcohol use, socioeconomic deprivation and ethnicity in older people. BMJ Open. 2015;5:e007525.

35. Geels LM, Vink JM, van Beek JH, Bartels M, Willemsen G, Boomsma DI. Increases in alcohol consumption in women and elderly groups: evidence from an epidemiological study. BMC Public Health. 2013;13:207.

36. Carrasco-Garrido P, Lopez De Andres A, Hernandez Barrera V, JimenezTrujillo I. Jimenez-Garcia R. National trends (2003-2009) and factors related to psychotropic medication use in community-dwelling elderly population. Int Psychogeriatr. 2013;25:328-38.

37. Soudry A, Dufouil C, Ritchie K, Dartigues JF, Tzourio C, Alpérovitch A. Factors associated with changes in antidepressant use in a community-dwelling elderly cohort: The Three-City study. Eur J Clin Pharmacol. 2008:64:51-9.

38. Parabiaghi A, Franchi C, Tettamanti M, Barbato A, D'Avanzo B, Fortino I, et al. Antidepressants utilization among elderly in Lombardy from 2000 to 2007: Dispensing trends and appropriateness. Eur J Clin Pharmacol. 2011;67:1077-83.

39. Sultana J, Italiano D, Spina E, Cricelli C, Lapi F, Pecchioli S, et al. Changes in the prescribing pattern of antidepressant drugs in elderly patients: An Italian, nationwide, population-based study. Eur J Clin Pharmacol. 2014;70:469-78.

40. Tilburt JC, Emanuel EJ, Miller FG. Does the evidence make a difference in consumer behavior? Sales of supplements before and after publication of negative research results. J Gen Intern Med. 2008:23:1495-98.

41. Ruscitto A, Smith BH, Guthrie B. Changes in opioid and other analgesic use 1995-2010: Repeated cross-sectional analysis of dispensed prescribing for a large geographical population in Scotland. Eur J Pain. 2015;19:59-66.

42. Steinman MA, Komaiko KDR, Fung KZ, Ritchie CS. Use of Opioids and Other Analgesics by Older Adults in the United States, 1999-2010. Pain Med. 2015; 16:319-27.

43. Campbell Cl, Weisner C, Leresche L, Ray GT, Saunders K, Sullivan MD, et al. Age and gender trends in long-term opioid analgesic use for noncancer pain. Am J Public Health. 2010;100:2541-47. 
44. Alessi-Severini S, Bolton JM, Enns MW, Dahl M, Collins DM, Chateau D, et al. Use of benzodiazepines and related drugs in Manitoba: a population-based study. CMAJ Open. 2014;2:E208-16.

45. Bijlsma MJ, Hak E, Bos J, De Jong-van den Berg LT, Janssen F. Assessing the effect of a guideline change on drug use prevalence by including the birth cohort dimension: the case of benzodiazepines. Pharmacoepidemiol Drug Saf. 2013;22:933-41.

46. laboni A, Bronskill S, Reynolds K, Wang X, Rochon P, Herrmann N, et al. Changing pattern of sedative use in older adults: a population-based cohort study. Drugs Aging. 2016;33(7):523-33.

47. Criado-Alvarez JJ, Romo Barrientos C. (Variability and trends in dementia drug consumption in Castile-La Mancha (Spain). Estimated prevalence of Alzheimer's disease]. Neurologia. 2010;25:234-8.

48. Lövheim H, Gustafson Y, Karlsson S, Sandman PO. Comparison of behavioral and psychological symptoms of dementia and psychotropic drug treatments among old people in geriatric care in 2000 and 2007. Int Psychogeriatr. 2011;23:1616-22.

49. Wold RS, Lopez ST, Yau CL, Butler LM, Pareo-Tubbeh SL, Waters DL, et al. Increasing trends in elderly persons' use of nonvitamin, nonmineral dietary supplements and concurrent use of medications. J Am Diet Assoc. 2005;105:54-63.

50. Kelly JP, Kaufman DW, Kelley K, Rosenberg L, Anderson TE, Mitchell AA. Recent trends in use of herbal and other natural products. Arch Intern Med. 2005;165:281-6.

51. Tsiropoulos I, Gichangi A, Andersen M, Bjerrum L, Gaist D, Hallas J. Trends in utilization of antiepileptic drugs in Denmark. Acta Neurol Scand. 2006;113:405-11.

52. Vasudev A, Shariff SZ, Liu K, Burhan AM, Herrmann N, Leonard S, et al. Trends in psychotropic dispensing among older adults with dementia living in long-term care facilities: 2004-2013. Am J Geriatr Psychiatry. 2015;23: 1259-69.

53. de Groot MC, Schuerch M, de Vries F, Hesse U, Oliva B, Gil M, et al. Antiepileptic drug use in seven electronic health record databases in Europe: a methodologic comparison. Epilepsia. 2014;55:666-73.

54. Holt S, Schmiedl S, Thürmann PA. PRISCUS-Liste potenziell inadäquate Medikation für ältere Menschen [PRISCUS-List potentialyl inappropriate medication for the elderly]. 2011 http://priscus.net/download/PRISCUSListe PRISCUS-TP3 2011.pdf. Accessed 26 May 2016.

55. Holt S, Schmiedl S, Thürmann PA. Potentially inappropriate medication in the elderly - PRISCUS list. Dtsch Arztebl Int. 2010;107:543-51.

56. Cui YH, Zheng Y. A meta-analysis on the efficacy and safety of St John's wort extract in depression therapy in comparison with selective serotonin reuptake inhibitors in adults. Neuropsychiatr Dis Treat. 2016;12:1715-23.

57. Papaleontiou M, Henderson Jr CR, Turner BJ, Moore AA, Olkhovskaya Y, Amanfo $L$, et al. Outcomes associated with opioid use in the treatment of chronic noncancer pain in older adults: a systematic review and metaanalysis. J Am Geriatr Soc. 2010;58:1353-69.

58. O'Neil CK, Hanlon JT, Marcum ZA. Adverse effects of analgesics commonly used by older adults with osteoarthritis: focus on non-opioid and opioid analgesics. Am J Geriatr Pharmacother. 2012;10:331-42.

59. Mojtabai R, Olfson M. National trends in long-term use of antidepressant medications: results from the us national health and nutrition examination survey. J Clin Psychiatry. 2014;75:169-77.

60. Sonnenberg CM, Bierman EJM, Deeg DJH, Comijs HC, Van Tilburg W, Beekman ATF. Ten-year trends in benzodiazepine use in the Dutch population. Soc Psychiatry Psychiatr Epidemiol. 2012;47:293-301.

61. Sullivan MD, Edlund MJ, Fan MY, Devries A, Brennan Braden J, Martin BC. Trends in use of opioids for non-cancer pain conditions 2000-2005 in commercial and Medicaid insurance plans: the TROUP study. Pain. 2008;138:440-49.

62. Braden JB, Fan MY, Edlund MJ, Martin BC, DeVries A, Sullivan MD. Trends in use of opioids by noncancer pain type 2000-2005 among Arkansas Medicaid and HealthCore enrollees: results from the TROUP study. J Pain. 2008;9:1026-35.

63. Nana GN, Doulougou B, Gomez F, Ylli A, Guralnik J, Zunzunegui MV. Social differences associated with the use of psychotropic drugs among men and women aged 65 to 74 years living in the community: The international mobility in aging study (IMIAS). BMC Geriatr. 2015;15:85.

64. Filho AlL, Castro-Costa E, Araújo Firmo JO, Sérgio Viana Peixoto SV. Trends in the use of antidepressants among older adults: Bambuí Project. Rev Saude Publica. 2014;48:857-65.

65. Blumstein T, Benyamini Y, Shmotkin D, Lerner-Geva L. Gender differences in the prevalence and correlates of psychotropic medication use among older adults in Israel. Isr J Psychiatry Relat Sci. 2014;51:118-27.
66. Hofer-Duckelmann C. Gender and polypharmacotherapy in the elderly: a clinical challenge. Handb Exp Pharmacol. 2012;214:169-82.

67. Bierman AS, Pugh MJ, Dhalla I, Amuan M, Fincke BG, Rosen A, et al. Sex differences in inappropriate prescribing among elderly veterans. Am J Geriatr Pharmacother. 2007;5:147-61.

68. Karger A. Gender differences in depression. Bundesgesundheitsblatt Gesundheitsforschung Gesundheitsschutz. 2014;57:1092-8.

\section{Submit your next manuscript to BioMed Central and we will help you at every step:}

- We accept pre-submission inquiries

- Our selector tool helps you to find the most relevant journal

- We provide round the clock customer support

- Convenient online submission

- Thorough peer review

- Inclusion in PubMed and all major indexing services

- Maximum visibility for your research

Submit your manuscript at www.biomedcentral.com/submit
) Biomed Central 